\title{
Ginkgo Extract EGb761 Confers Neuroprotection by Reduction of Glutamate Release in Ischemic Brain
}

\author{
Alexander Mdzinarishvilia, ${ }^{\mathrm{a} b}$, Rachita Sumbria ${ }^{\mathrm{a}}$, Dorothee Lang $^{\mathrm{c}}$ and Jochen Klein ${ }^{\mathrm{a}, \mathrm{c}}$ \\ ${ }^{a}$ Department of Pharmaceutical Sciences, School of Pharmacy, Texas Tech University Health Science Center, \\ Amarillo, Texas, USA. \\ ${ }^{\mathrm{b}}$ Department of Pharmaceutical Sciences, Northeastern Ohio Medical University College of Pharmacy, Ohio, USA. \\ ${ }^{\mathrm{c}}$ Department of Pharmacology, College of Pharmacy, Goethe University Frankfurt, Germany.
}

Received, October 12, 2011; Revised, November 19, 2011; Accepted, January 5, 2012; Published, January 5, 2012.

\begin{abstract}
Purpose - Ginkgo extract EGb761 has shown anti-edema and anti-ischemic effects in various experimental models. In the present study, we demonstrate neuroprotective effects of EGb761 in experimental stroke while monitoring brain metabolism by microdialysis. Methods - We have used oxygenglucose deprivation in brain slices in vitro and middle cerebral artery occlusion (MCAO) in vivo to induce ischemia in mouse brain. We used microdialysis in mouse striatum to monitor extracellular concentrations of glucose and glutamate. Results - In vitro, EGb761 reduced ischemia-induced cell swelling in hippocampal slices by $60 \%$. In vivo, administration of EGb761 $(300 \mathrm{mg} / \mathrm{kg})$ reduced cell degeneration and edema formation after MCAO by $35-50 \%$. Immediately following MCAO, striatal glucose levels dropped to $25 \%$ of controls, and this reduction was not significantly affected by EGb761. Striatal glutamate levels, in contrast, increased 15-fold after MCAO; after pretreatment with EGb761, glutamate levels only increased by 4-5fold. Conclusions - We show that pretreatment with EGb761 strongly reduces cellular edema formation and neurodegeneration under conditions of ischemia. The mechanism of action seems to be related to a reduction of excitotoxicity, because ischemia-induced release of glutamate was strongly suppressed. Ginkgo extracts such as EGb761 may be valuable to prevent ischemia-induced damage in stroke-prone patients.
\end{abstract}

This article is open to POST-PUBLICATION REVIEW. Registered readers (see "For Readers") may comment by clicking on ABSTRACT on the issue's contents page.

\section{INTRODUCTION}

Extracts of Ginkgo biloba such as EGb 761 are widely used for the treatment of progressive neurodegenerative disorders such as Alzheimer's disease [1,2]. Experimental work during the last twenty years has also shown that Ginkgo extracts and their constituents, such as ginkgolides and bilobalide, exert beneficial effects in animal models of acute neurodegeneration, e.g. in cerebral hypoxia and ischemia [3-6].

In our previous studies, we have characterized the strong neuroprotective properties of bilobalide, a sesquiterpene trilactone that represents $3 \%$ of EGb761 [7,8]. In vivo, bilobalide (given i.p. at $10 \mathrm{mg} / \mathrm{kg}$ ) decreased infarct area as well as edema formation after middle cerebral artery occlusion (MCAO) in mice [9]. However, other constituents of EGb761, such as flavonoids ( $24 \%$ of the extract) and ginkgolides (another 3\%) [10], have been suggested to contribute to the extract's beneficial activities in models of neuronal degeneration (reviewed in [11]).

The mechanism of action of EGb761 remains unknown but several hints have been followed. Flavonoids have antioxidative properties which may contribute to neuroprotection, and ginkgolide $\mathrm{B}$ is known to inhibit thrombocyte aggregation in high doses [12]. Bilobalide has been found to improve mitochondrial activity and to preserve ATP levels during ischemia [3,13]. We have investigated interactions of bilobalide with amino acid neurotransmitters such as GABA, glycine, and glutamate $[14,15]$. Very recently, several constituents of EGb761 were implied in the induction of heme oxygenase-1 in ischemic neurons [16]. In the present study, we investigated neuroprotective effects of EGb761 in an in vitromodel of brain ischemia, namely brain slices exposed to oxygen-glucose deprivation, and in an in vivo-model of experimental stroke, middle cerebral artery occlusion (MCAO) in mice. Combining MCAO with microdialysis, we were able to monitor extracellular concentrations of glucose and glutamate by microdialysis. We obtained evidence that neuroprotection by EGb761 is accompanied by a reduction of excitotoxicity, caused by a reduction of ischemiainduced release of glutamate.

Corresponding Author: Jochen Klein, Ph.D., Professor of Pharmacology and Clinical Pharmacy, Goethe University of Frankfurt, Biozentrum N260, Max-von-Laue-Str. 9, 60438 Frankfurt, Germany. E-mail: klein@em.uni-frankfurt.de 


\section{METHODS}

\section{Animals}

Female CD-1 mice with a weight of $28-32 \mathrm{~g}$ (Charles River, Wilmington, MA), and male Wistar rats $(250-350 \mathrm{~g})$ were kept under standardized 12 -h light/dark, temperature $\left(22^{\circ} \mathrm{C}\right)$ and humidity $(70 \%)$ conditions, with food and water available ad libitum. All animal procedures were in accordance with NIH regulations and were registered with the Institutional Animal Care and Use Committee of TTUHSC. All efforts were made to minimize animal numbers and animal suffering.

\section{Ginkgo extract EGb761}

This standardized extract was manufactured and analyzed for constituents by the manufacturer (Schwabe Co., Karlsruhe, Germany) as described in [10]. The extract contains $24 \%$ flavonoids (e.g. kampferol, quercetin) and 6\% ginkgolides, of which $3.0 \pm 0.1 \%$ are bilobalide [10]. The extract is stable when kept cold and dry and was freshly dissolved in $\mathrm{DMSO} /$ water for the present experiments.

\section{Edema formation in hippocampal slices}

Rats were briefly anesthetized with isoflurane and decapitated. Hippocampal slices $(400 \mu \mathrm{m})$ were prepared as previously described $[8,9]$ and superfused $(0.7 \mathrm{ml} / \mathrm{min})$ at $35^{\circ} \mathrm{C}$ with Tyrode solution of the following composition: $\mathrm{NaCl}, 137$ $\mathrm{mM} ; \mathrm{KCl}, 2.7 \mathrm{mM} ; \mathrm{CaCl}_{2}, 1.8 \mathrm{mM} ; \mathrm{MgCl}_{2}$, $1.2 \mathrm{mM} \mathrm{mM} ; \mathrm{NaH}_{2} \mathrm{PO}_{4}, 0.2 \mathrm{mM} ; \mathrm{NaHCO}_{3}, 11.9$ $\mathrm{mM}$; glucose, $5.6 \mathrm{mM}$. During the equilibration period, all superfusion solutions were continuously gassed with carbogen $\left(95 \% \mathrm{O}_{2}, 5 \%\right.$ $\mathrm{CO}_{2}$ ). For in vitro-ischemia (OGD, oxygenglucose deprivation), the slices were superfused with solutions which did not contain glucose and which had been gassed with nitrogen instead of oxygen $\left(95 \% \mathrm{~N}_{2}, 5 \% \mathrm{CO}_{2}\right)$. EGb761 $(300 \mu \mathrm{M})$ was added in DMSO; control solutions contained the same amount of DMSO $(0.1 \%)$ as extractcontaining solutions. Four lanes of slices were superfused in parallel for 30 minutes. At the end of the superfusion period, slices from each lane were collected, superficially dried, transferred to aluminum foil, and weighed ("wet weight"). They were then dried overnight at $105^{\circ} \mathrm{C}$ in a desiccating oven and weighed again ("dry weight"). Slice water content was calculated according to [(wet weight - dry weight)/ wet weight] $\mathrm{x} 100$.

\section{Microdialysis experiments}

Mice were anesthetized with isoflurane (induction dose $4 \%$, maintenance dose $1-1.5 \% \mathrm{v} / \mathrm{v}$ ) in a
$25 \% / 75 \%$ mixture of oxygen and nitrous oxide and placed in a stereotaxic frame. Self-made, Yshaped, concentric dialysis probes with an exchange length of $2.5 \mathrm{~mm}$ were implanted in the left striatum using the following coordinates (from bregma): AP $+0.5 \mathrm{~mm}$; $\mathrm{L}+2.2 \mathrm{~mm}$; DV $3.8 \mathrm{~mm}$ [17]. The mice were allowed to recover over night. On the next day, the microdialysis probes were perfused with artificial cerebrospinal fluid (aCSF; $147 \mathrm{mM} \mathrm{NaCl}, 4 \mathrm{mM} \mathrm{KCl}, 1.2 \mathrm{mM}$ $\mathrm{CaCl}_{2}$ and $1.2 \mathrm{mM} \mathrm{MgCl}_{2}$ ). The perfusion rate was $1.5 \mu \mathrm{L} / \mathrm{min}$ and efflux from the microdialysis probe was collected in intervals of $15 \mathrm{~min}$. After equilibration of $30 \mathrm{~min}$, animals were injected with EGb761 (300 mg/kg i.p.; the extract was dissolved in saline containing 10\% DMSO), and dialysate samples were collected for four hours before and after MCAO (see below) and assayed for metabolites.

\section{Middle cerebral artery occlusion experiments (MCAO)}

In vivo-ischemia in the brain was induced one day after microdialysis probe implantation (see above) as described in detail previously $[9,18]$. Briefly, the mice were anesthetized with $1.5 \%$ isofluorane in $30 \% \mathrm{O}_{2} / 70 \% \mathrm{~N}_{2} \mathrm{O}$. The skin was incised, and the left occipital and superior thyroid artery, branches of the external carotid artery (ECA), as well as the pterygopalatine artery were exposed, electrocoagulated, and cut. After occlusion of the common carotid artery by microclip, the left ECA was ligated, coagulated and cut distally to the cranial thyroid artery. A $15 \mathrm{~mm}$ monofilament nylon suture (5-0, Harvard Apparatus, Holliston, MA, USA; diameter of the heat-rounded tip: 0.2$0.3 \mathrm{~mm}$ ) was inserted into the ECA and gently advanced through the internal carotid artery until its tip occluded the origin of the middle cerebral artery (MCA). Correct placement of the suture was monitored by a sudden drop of the local cortical blood flow in the left MCA territory to $10-20 \%$ of basal flow as monitored by laserDoppler flowmetry. After successful occlusion, the monofilament was secured in place with ligature, and the skin incision was closed by surgical clips. Throughout surgery, temperature was maintained at $37^{\circ} \mathrm{C}$ by a thermostatic blanket (rectal thermometer). EGb761 (or vehicle, 10\% DMSO in saline) was injected intraperitoneally 60 min before induction of ischemia at a dose of 300 $\mathrm{mg} / \mathrm{kg}$. MCAO was sustained for a period of $24 \mathrm{~h}$ ("permanent occlusion"), after which the animals were deeply anesthetized with isoflurane and euthanized by decapitation. The brains were quickly removed, sectioned coronally into $1 \mathrm{~mm}$ slices, and stained with 2,3,5-triphenyltetrazolium chloride (TTC). Images were acquired 
by digital camera, and areas of both hemispheres and the infarcted regions were quantified for each slice using Image J 1.30. Brain edema (brain swelling) were quantified by comparing the area of the ipsilateral (ischemic) hemisphere to the contralateral (non-ischemic) hemisphere ("hemispheric ratio"), as described previously $[19,20]$.

\section{Chemical analysis of microdialysates}

Metabolite concentrations in the microdialysis samples were determined by a CMA 600 microanalyzer (CMA, Stockholm, Sweden) using a kinetic photometric assay as described by the manufacturer. The following metabolites were measured (lower limits of detection in parentheses): glucose $(0.02 \mathrm{mM})$, lactate $(0.02$ $\mathrm{mM})$, and glutamate $(1.0 \mu \mathrm{M})$. In vitro-recoveries were determined by dialysis of analytes from unstirred vials containing a fixed concentration (100-times the detection limit) of analytes.

\section{STATISTICS}

All values are represented as means \pm SEM of $n$ experiments. GraphPad Prism 5.0® was used for statistical analysis (t-test, one-way ANOVA or two-way ANOVA; for details, see figure legends).

\section{RESULTS}

In vitro model of brain edema formation

Rat hippocampal slices is a good in vitro-model to test anti-edema effects because the hippocampus is very sensitive towards ischemia-induced cell swelling [21]. In this experiment, edema formation in slices was quantified by measuring slice water contents using a differential weighing method as previously described [9,22]. After 30 min of superfusion with control buffer (Tyrode solution), the water content of the slices was 81.0 $\pm 0.61 \%$ (mean \pm SEM, N=9; Fig. 1A). To mimic ischemic conditions, the slices were exposed to oxygen-glucose deprivation (OGD), i.e. glucose was omitted from the superfusion buffer which was also gassed with nitrogen [9,22]. Exposure of the slices to OGD increased water content by 2.93 $\pm 0.54 \%(\mathrm{p}<0.01$; Fig. 1B). In the presence of EGb761, slice water contents under control conditions were slightly but not significantly increased (Fig. 1A). Importantly, EGb761 largely prevented edema formation induced by OGD; in the presence of EGb761, the OGD-induced increase of water content was $1.16 \pm 0.40 \%$ when compared to incubations with EGb761 alone $(p<0.01$; Fig. 1B). This corresponds to an inhibition of edema formation by $60 \%$.
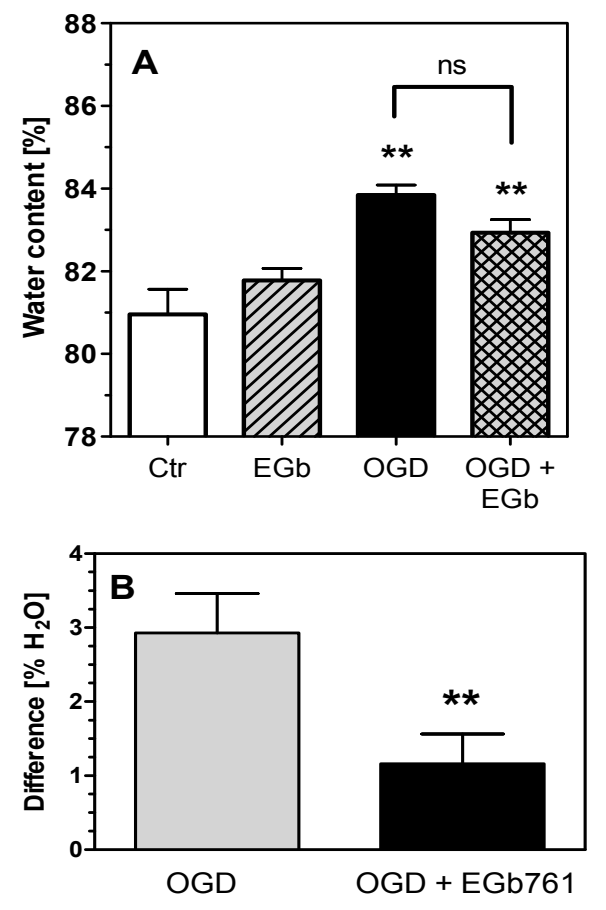

Figure 1. Tissue water content in hippocampal slices. (A) Effects of EGb761 $(300 \mu \mathrm{M})$ on tissue edema formation induced by oxygen-glucose-deprivation (OGD). (B) Comparison of OGD-induced increases of water content in the absence and presence of EGb761. Data in (A) are absolute values, data in (B) are expressed as differences from control incubations. Statistical significance was evaluated by paired ANOVA (A) or t-test (B). **, $\mathrm{p}<0.01$ vs controls (Ctr) in $\mathrm{A}$ and vs. OGD in $\mathrm{B}$ (all mean $\pm \mathrm{SEM}, \mathrm{N}=9$ ). 


\section{Brain edema formation induced by ischemic stroke in vivo}

Middle cerebral artery occlusion (MCAO) in mice was used to induce focal cerebral ischemia in vivo; in this paradigm, blood flow in the corpus striatum is severely reduced ("core region" of the infarct) by $>80 \%$ causing cell death within few hours. Fig. 2 shows a representative experiment in which infarct areas in striatal slices were stained 24 hours after permanent MCAO. The areas of non-viable tissue, as indicated by pale color, were much smaller in the infarcted hemisphere when animals were pretreated with EGb761 $(300 \mathrm{mg} / \mathrm{kg}$ i.p.) one hour before MCAO (Fig. 2, right panel), compared to controls which were treated with vehicle (Fig. 2, left panel).

Fig. 3A shows the averaged infarct areas as found in consecutive coronal slices; slices 1,2 and 3 correspond to striatal slices, slices 4 and 5 to hippocampal-thalamic areas. When infarct areas were calculated by averaging individual slices, the infarct areas in slices 2, 3 and 4 were significantly smaller in EGB761-treated mice than in vehicletreated controls. In addition to infarct area, we also calculated the formation of edema in vivo by comparing the size of infarcted and contralateral hemispheres as described before ("hemispheric enlargement"; $[19,20]) .24$ hours after MCAO, the ischemic side of the brain showed significant swelling (see also Fig. 2). Tissue swelling and edema formation was higher in control mice in all slices; the differences were significant for slices 3, 4 and 5 (Fig. 3B).

\section{Effects of EGb761 pretreatment on extracellular levels of glucose and glutamate}

By combining microdialysis and the experimental stroke model, we were able to monitor brain neurochemistry in situ in mouse striatum, the core area of the infarct, before and after ischemia. The microdialysis probe only has access to the extracellular space, hence, measured values reflect extracellular concentrations. Basal levels of striatal glucose before ischemia were $0.18 \pm$ $0.20 \mathrm{mM}$ (mean $\pm \mathrm{SEM}, \mathrm{N}=7$ ) and remained largely unchanged during microdialysis in shamoperated mice (Fig. 4A). After MCAO, striatal glucose levels immediately declined by more than $50 \%$ within 15-30 minutes (Fig. 4A) and remained low at $20-30 \%$ of basal levels throughout the experiment (Fig. 4A); this is likely due to consumption of local glucose and lack of supply of fresh glucose due to limited blood flow [23]. Pretreatment with EGb761 did not strongly affect the changes due to ischemia indicating that neither blood supply nor consumption of glucose was affected by the extract to a relevant extent (Fig. 4A).
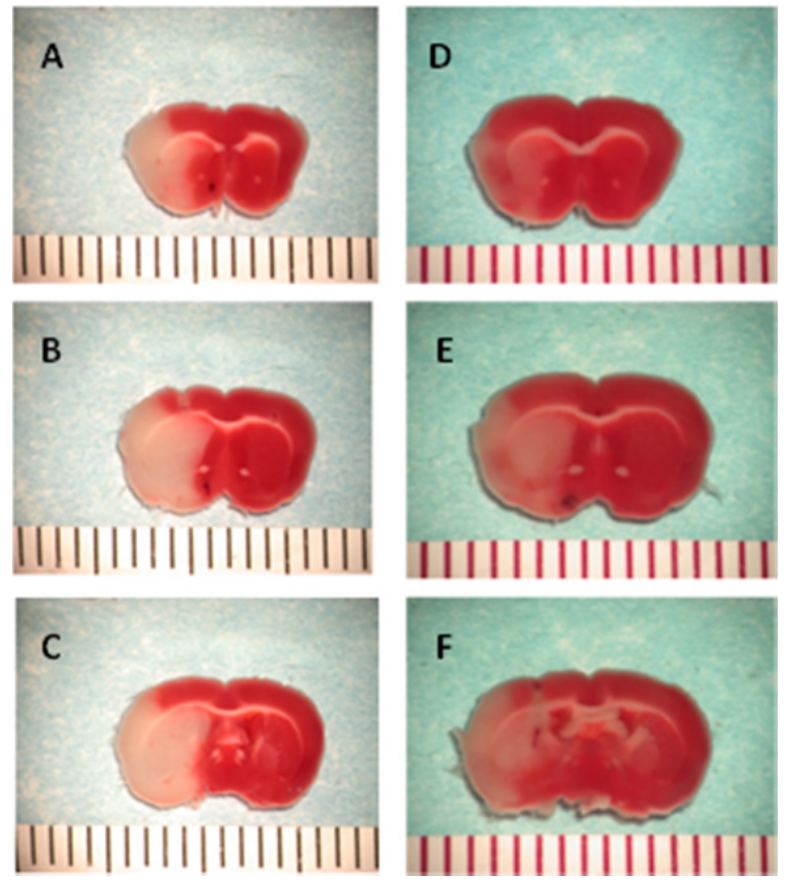

Figure 2. Effects of EGb761 on cell death induced by permanent middle cerebral artery occlusion (MCAO) in the mouse striatum. Left panel (A-C): Striatal slices from a mouse treated with vehicle $(0.3 \mathrm{ml}$ saline i.p. containing $10 \%$ DMSO) one hour prior to MCAO. Right panel (D-F): Striatal slices from a mouse treated with EGb761 (300 mg/kg i.p.) one hour prior to MCAO. The animals were sacrificed 24 hours after MCAO, and five slices of $1 \mathrm{~mm}$ thickness were cut coronally and stained by TTC (see Methods). Areas with insufficient mitochondrial activity to reduce TTC are indicated by pale white color. 

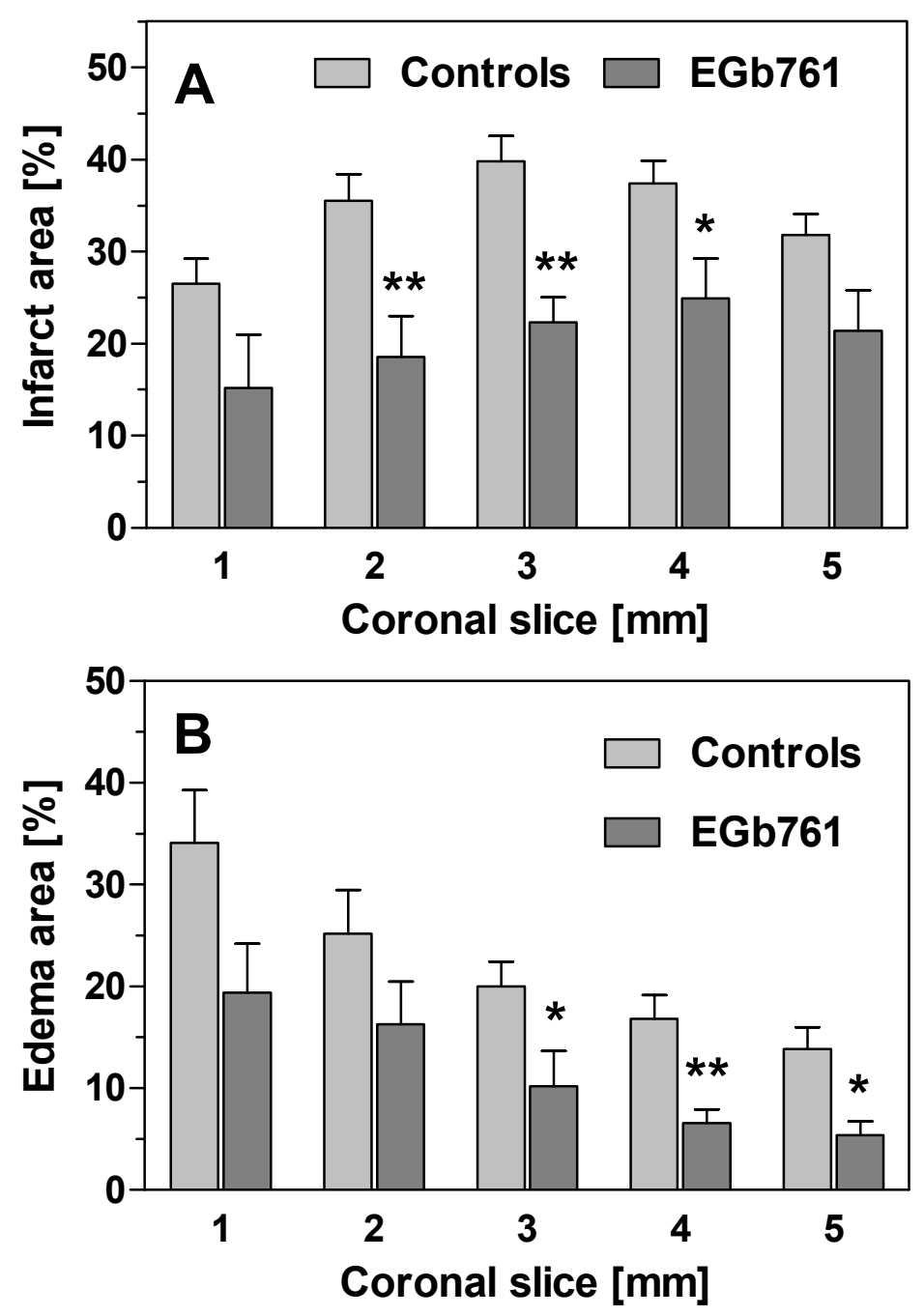

Figure 3. Effects of EGb761 on (A) infarct area and (B) edema formation induced by permanent middle cerebral artery occlusion (MCAO) in the mouse. Infarct areas and edema ratios were measured 24 hours after MCAO in consecutive brain slices taken (cf. Fig. 2) from mice pretreated with vehicle (controls) or EGb761 (300 mg/kg i.p.). Infarct areas in (A) were calculated as percentage of infarct areas over total brain area in each slice and averaged over five animals. Edema formation was calculated as hemispheric enlargement and is given as percentages (relative increase of the brain area in the infarcted hemisphere vs. the contralateral hemisphere). Statistical significance was evaluated by $\mathrm{t}$-test. *, $\mathrm{p}<0.05 ; * *, \mathrm{p}<0.01$ vs Controls. Results are mean $\pm \mathrm{SEM}, \mathrm{N}=5$.

In contrast to glucose, extracellular glutamate levels increase dramatically during ischemia; ischemia is known to lead to the release of large amounts of glutamate from brain cells, a phenomenon that causes massive neurodegeneration by excitotoxicity $[24,25]$. In our present experiments, the extracellular concentration of glutamate in the striatum was $2.35 \pm 0.82 \mu \mathrm{M}$ before ischemia (mean $\pm \mathrm{SEM}$, $\mathrm{N}=7$ ). Glutamate remained at low levels in shamoperated mice; upon MCAO, however, we observed an immediate, very prominent increase of striatal glutamate by (on average) $1500 \%$ (Fig. 4B). Glutamate levels decreased slowly thereafter but remained strongly elevated for several hours. Most importantly, in mice pretreated with EGb761, glutamate release was strongly attenuated. After MCAO, glutamate increased in a more delayed fashion reaching $400-500 \%$ of basal levels (Fig. 4B). The effect of EGb761 treatment on glutamate levels was highly significant $(\mathrm{p}<0.001)$.

It should be mentioned that we also measured extracellular concentrations of lactate; however, lactate levels were strongly increased at the onset of anesthesia with isoflurane and therefore, were of little significance to monitor ischemia in our experiments (see [26] for further discussion). 

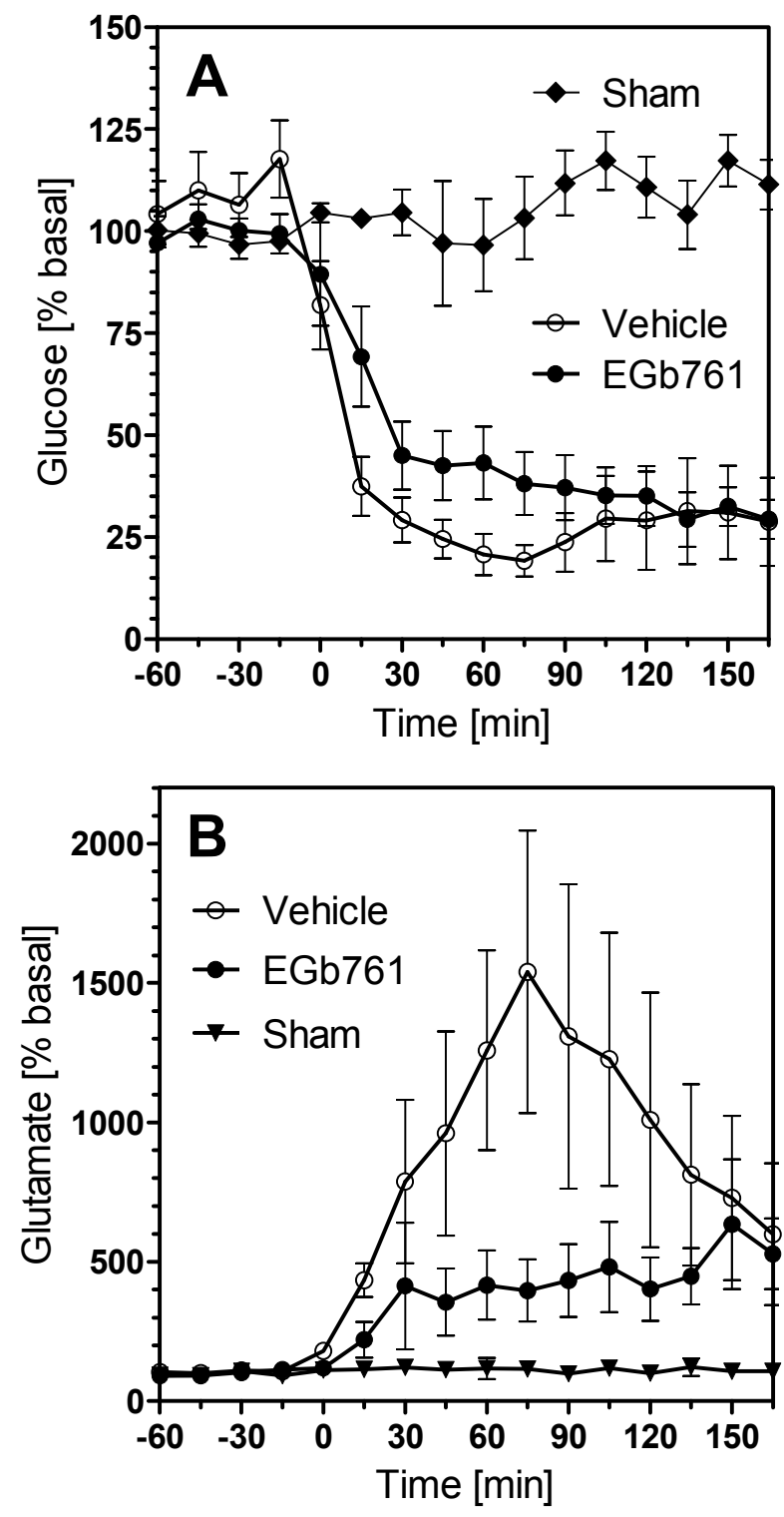

Figure 4. Effects of EGb761 on extracellular (A) glucose and (B) glutamate levels in mouse striatum before and after permanent MCAO. The figures show concentrations measured from $60 \mathrm{~min}$ before induction of stroke (MCAO, at time zero) to 165 min past stroke. Experiments were done in three groups of mice: sham-operated mice ("Sham"), vehicletreated mice with MCAO ("Vehicle") and EGb761-treated mice with MCAO ("EGb761") (N=6 each). EGb761 was dissolved in vehicle (10\% DMSO in saline) and was given by i.p. injection one hour before MCAO at a dose of 300 $\mathrm{mg} / \mathrm{kg}$. Data are percentages (means $\pm \mathrm{SEM}$ ) of basal concentrations which were determined as averages from the measured samples prior to MCAO (see Results for basal values). Statistical analysis (two-way ANOVA, GraphPad Prism ${ }^{\circledR}$ ): (A) glucose ("Vehicle") vs. glucose ("EGb761"), $\mathrm{F}_{1,160}=4.65, \mathrm{p}=0.03$. (B) glutamate ("Vehicle") vs. glutamate ("EGb761"), $\mathrm{F}_{1,160}=19.96 ; \mathrm{p}<0.001$.

\section{DISCUSSION}

Ginkgo extract EGb761, well known as a treatment for dementia, a disease of chronic neurodegeneration, has neuroprotective properties that may make it useful as a treatment for acute neurodegeneration e.g. after stroke. We here report that EGb761 has anti-edema and neuroprotective effects in vitro, in a slice model of ischemia, as well as in vivo, after permanent $\mathrm{MCAO}$ in mice. By combining microdialysis with MCAO, we provide evidence that EGb761 attenuates ischemia-induced release of glutamate in the core region of the infarct.

Can inhibition of glutamate release explain neuroprotective activity of the extract ? Previous 
research has demonstrated that the increase of glutamate is one of the major culprits for ischemia-induced neurodegeneration because it causes "excitotoxicity", i.e. massive neuronal depolarisation and calcium overload (reviewed in [24,25]). Blockade of glutamate neurotransmission, e.g. by antagonists at the NMDA receptor, confer neuroprotection in vitro and in vivo. Reduction of glutamate release is an even earlier phenomenon and would prevent postsynaptic toxicity of glutamate at all glutamate receptors. Neurons would suffer from reduced depolarization and reduced calcium influx, and may be more apt to deal with excitation. Preserved mitochondrial function ATP levels would explain the reduction of infarct area (Figs. 2 and 3B). Moreover, reduction of glutamate release could also explain the anti-edema actions of the extract (Fig. 1 and 3B). Brain edema formation is one of the most dangerous consequences of ischemic brain injury [27]. Brain swelling that occurs early after stroke is known to be due to cytotoxic edema while vasogenic edema develops in a more delayed fashion (over hours). In previous studies using hippocampal slices, an increase of sodium and calcium uptake was observed to which voltage-operated cation channels as well as glutamate receptors of the AMPA and NMDA subtypes contributed [22,28]. In our hands, EGb761 was similarly active as glutamate receptor antagonists tested in previous studies $[22,28]$.

The constituents of EGb761 that have been suggested to be responsible for neuroprotection are ginkgolides including bilobalide, and flavonoids. Both classes of compounds occur prominently in Ginkgo extracts, and they reach micromolar concentrations after intake of Ginkgo extract EGb761 in human and experimental studies [29]. Moreover, both classes of compounds have recently been shown to cross the blood-brain barrier in significant amounts [30,31]. However, bilobalide may be the most active constituent of the extract. As EGb761 contains $3.0 \%$ of bilobalide [10], the dose of $300 \mathrm{mg} / \mathrm{kg}$ used here corresponds to $9 \mathrm{mg} / \mathrm{kg}$ of bilobalide. In a previous study using pure bilobalide, we observed strong neuroprotective effects at 10 $\mathrm{mg} / \mathrm{kg}$ of drug [9]. Moreover, bilobalide is known to protect mitochondrial function and $\mathrm{Na}, \mathrm{K}$ ATPase activity under conditions of ischemia $[3,4]$. We speculate, therefore, that bilobalide may explain all or a major part of the neuroprotective activity of EGb761 in the stroke model.

Can EGb761 be used to prevent strokeinduced damage ? Many years of work on neuroprotective compounds has often resulted in hopeful results in experimental studies which could not be reproduced in clinical trials [32]. Poor brain permeability and insufficient time windows of action are two major reasons why promising neuroprotective drugs have failed under clinical conditions [32]. As indicated above, constituents of EGb761 are brainpermeable; moreover, in clinical dementia trials, Ginkgo extract EGb761 has been almost devoid of side effects although a potential to inhibit blood coagulation is still under discussion [1,2]. EGb761 may, therefore, be a drug that could be used in a prophylactic manner in stroke-prone patients, e.g. patients with long-standing, therapyresistant hypertension or patients previously suffering from transient ischemic attacks. In contrast, Ginkgo extracts lack efficacy when given in the post-stroke recovery period [33]. This could be explained by its action on the rapid release of glutamate which evokes excitotoxicity within the first minutes to hours of ischemia.

Lastly, it is important to note that we measured stroke-induced damage only after 24 hours in this study when neuroprotection was seen even in the core region of the stroke, the striatum. Further work is required to document whether survival of cells (Fig. 2) translates into improved functional outcomes. It is possible that EGb761 did not completely prevent neurodegeneration but only delayed it. In this case, treatment with EGb761 alone may have limited effects for the neurodegeneration observed after several days. EGb761 would still be helpful, however, to extend the time window for thrombolytic therapy which - in the absence of neuroprotection - is only active for 3-4.5 hours after stroke [34]. This limited time window is often difficult to match under clinical conditions so that thrombolytic therapy with tPA is initiated for only a minority of patients. Pretreatment of suspected stroke victims with EGb761, however, may delay neuronal death and extend the time window for thrombolytic therapy.

\section{ACKNOWLEDGEMENTS}

We thank Dr. Willmar Schwabe GmbH for generously providing EGb761. This study was financed by NIH/NCCAM 5R21AT3399-3, and by internal funds of Goethe University.

\section{REFERENCES}

1. Ramassamy C, Longpre F, Christen Y. Ginkgo biloba extract (EGb 761) in Alzheimer's disease: is there any evidence ? Curr. Azheimer Res. 2007; 4: 253-262. 
2. Birks J, Grimley EJ. Ginkgo biloba for cognitive impairment and dementia. Cochrane Database Syst Rev 2009; CD003120.

3. Pierre S, Jamme I, Droy-Lefaix MT, Nouvelot A, Maixent JM. Ginkgo biloba extract (EGb 761) protects $\mathrm{Na}, \mathrm{K}$-ATPase activity during cerebral ischemia in mice. Neuroreport 1999; 10: 47-51.

4. Chandrasekaran K, Mehrabian Z, Spinnewyn B, Drieu K, Fiskum G. Neuroprotective effects of bilobalide, a component of the Ginkgo biloba extract (EGb 761), in gerbil global brain ischemia. Brain Res. 2001; 922: 282-292.

5. Lee EJ, Chen HY, Wu TS, Chen TY, Ayoub IA, Maynard KI. Acute administration of Ginkgo biloba extract (EGb 761) affords neuroprotection against permanent and transient focal cerebral ischemia in Sprague-Dawley rats. J. Neurosci. Res. 2002; 68: 636-645.

6. Paganelli RA, Benetoli A, Milani H. Sustained neuroprotection and facilitation of behavioral recovery by the Ginkgo biloba extract, EGb 761, after transient forebrain ischemia in rats. Behav. Brain Res. 2006; 174: 70-77.

7. Klein J, Chatterjee SS, Loffelholz K. Phospholipid breakdown and choline release under hypoxic conditions: inhibition by bilobalide, a constituent of Ginkgo biloba. Brain Res. 1997; 755: 347-350.

8. Weichel O, Hilgert M, Chatterjee SS, Lehr M, Klein J. Bilobalide, a constituent of Ginkgo biloba, inhibits NMDA-induced phospholipase $\mathrm{A}_{2}$ activation and phospholipid breakdown in rat hippocampus. Naunyn Schmiedebergs Arch. Pharmacol. 1999; 360: 609-615.

9. Mdzinarishvili A, Kiewert C, Kumar V, Hillert M, Klein J. Bilobalide prevents ischemia-induced edema formation in vitro and in vivo. Neuroscience 2007; 144: 217-222.

10. DeFeudis FV. Ginkgo biloba extract (EGb 761): from chemistry to the clinic. Ullstein Medical, Wiesbaden 1998.

11. Ahlemeyer B, Krieglstein J. Neuroprotective effects of Ginkgo biloba extract. Cell. Mol. Life Sci. 2003; 60: 1779-1792.

12. PanettaT, Marcheselli VL, Braquet P, Spinnewyn B, Bazan NG. Effects of a platelet activating factor antagonist (BN 52021) on free fatty acids, diacylglycerols, polyphosphoinositides and blood flow in the gerbil brain: inhibition of ischemiareperfusion induced cerebral injury. Biochem. Biophys. Res. Comm. 1987; 149: 580-587.

13. Abdel-Kader R, Hauptmann S, Keil U, Scherping I, Leuner K, Eckert A, Müller WE. Stabilization of mitochondrial function by Ginkgo biloba extract (EGb 761). Pharmacol. Res. 2007; 56: 493-502.

14. Kiewert C, Kumar V, Hildmann O, Rueda M, Hartmann J, Naik RS, Klein J. Role of GABAergic antagonism in the neuroprotective effects of bilobalide. Brain Res. 2007; 1128: 7078 .

15. Kiewert C, Kumar V, Hildmann O, Hartmann J, Hillert M, Klein J. Role of glycine receptors and glycine release for the neuroprotective activity of bilobalide. Brain Res. 2008; 1201: 143-150.
16. Shah ZA, Nada SE, Dore S. Heme oxygenase-1, beneficial role in permanent ischemic stroke and in Ginkgo biloba (EGb 761) neuroprotection. Neuroscience 2011; 180: 248-255.

17. Franklin KB, Paxinos G. The mouse brain in stereotaxic coordinates. Academic Press, San Diego 1997.

18. Mdzinarishvili A, Geldenhuys WJ, Abbruscato TJ, Bickel U, Klein J, Van der Schyf CJ. NGP1-01, a lipophilic polycyclic cage amine, is neuroprotective in focal ischemia. Neurosci. Lett. 2005; 383: 49-53.

19. Kinouchi H, Epstein CJ, Mizui T, Carlson E, Chen $\mathrm{SF}$, Chan PH. Attenuation of focal cerebral ischemic injury in transgenic mice overexpressing $\mathrm{CuZn}$ superoxide dismutase. Proc. Natl. Acad. Sci. USA 1991; 88: 11158-11162.

20. Sydserff SG, Green AR, Cross AJ. The effect of oedema and tissue swelling on the measurement of neuroprotection; a study using chlormethiazole and permanent middle cerebral artery occlusion in rats. Neurodegeneration 1996; 5: 81-85.

21. Schmidt-Kastner R, Freund TF. Selective vulnerability of the hippocampus in brain ischemia. Neuroscience 1991; 40: 599-636.

22. MacGregor DG, Avshalumov MV, Rice ME. Brain edema induced by in vitro ischemia: causal factors and neuroprotection. J. Neurochem. 2003; 85: $1402-1411$.

23. Kiewert C, Mdzinarishvili A, Hartmann J, Bickel U, Klein J. Metabolic and transmitter changes in core and penumbra after middle cerebral artery occlusion in mice. Brain Res. 2010; 1312: 101107.

24. Lipton P. Ischemic cell death in brain neurons. Physiol. Rev. 1999; 79: 1431-1568.

25. Szydlowska K, Tymianski M. Calcium, ischemia and excitotoxicity. Cell Calcium 2010; 47: 122-129.

26. Horn T, Klein J. Lactate levels in the brain are elevated upon exposure to volatile anesthetics: a microdialysis study. Neurochem. Int. 2010; 57: 940-947.

27. Kimelberg HK. Water homeostasis in the brain: basic concepts. Neuroscience 2004; 129: 851-860.

28. LoPachin RM, Gaughan CL, Lehning EJ, Weber ML, Taylor CP. Effects of ion channel blockade on the distribution of $\mathrm{Na}, \mathrm{K}, \mathrm{Ca}$ and other elements in oxygen-glucose deprived CA1 hippocampal neurons. Neuroscience 2001; 103: 971-983.

29. Biber A. Pharmacokinetics of Ginkgo biloba extracts. Pharmacopsychiatry 2003; 36 Suppl 1: S32-S37.

30. Ude C, Paulke A, Nöldner M, Schubert-Zsilavecz M, Wurglics M. Plasma and brain levels of terpene trilactones in rats after an oral single dose of standardized Ginkgo biloba extract EGb 761. Planta Med. 2011; 77: 259-264.

31. Lang D, Ude C, Wurglics M, Schubert-Zsilavecs M, Klein J. Brain permeability of bilobalide as probed by microdialysis before and after middle cerebral artery occlusion in mice. J. Pharm. Pharm. Sci. 2010; 13: 607-614. 
32. Ginsberg MD. Neuroprotection for ischemic stroke: Past, present and future. Neuropharmacology 2008; 55: 363-389.

33. Zeng X, Liu M, Yang Y, Li Y, Asplund K. Ginkgo biloba for acute ischemic stroke. Cochrane Database Syst Rev 2005; 4: CD003691.
34. Doyle KP, Simon RP, Stenzel-Poore MP. Mechanisms of ischemic brain damage. Neuropharmacology 2008; 55: 310-318. 